\title{
Clinical outcome of anterior cruciate ligament reconstruction with modified transtibial and anteromedial portal
}

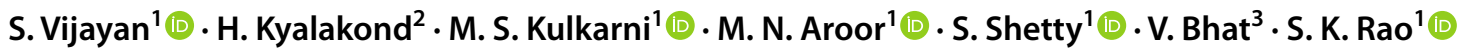

Received: 27 October 2020 / Accepted: 4 August 2021 / Published online: 13 August 2021

(c) The Author(s) 2021

\begin{abstract}
Arthroscopic ACL reconstruction is the current standard care of treatment for anterior cruciate ligament (ACL) injuries. Modified transtibial (mTT) and anteromedial portal (AMP) techniques aim at the anatomical placement of femoral tunnel. Controversy existed in the literature with regard to the outcome of these techniques. Hence, we designed a retrospective comparative study to analyse the clinical and functional outcomes of mTT and AMP techniques. We hypothesized that there would be no difference between the clinical and functional outcomes in mTT and AMP techniques. This retrospective observational study was conducted in consecutive patients who underwent arthroscopic ACL reconstruction using semitendinosus-gracilis (STG) quadrupled graft in our tertiary care centre with a minimum follow-up of two years. Out of 69 patients, 37 had undergone ACL reconstruction by mTT technique and remaining by AMP technique. All the patients were assessed clinically by anterior drawer, Lachman's, pivot shift and single-legged hop test. Lysholm Knee Scoring Scale and International Knee Documentation Committee (IKDC) subjective knee evaluation score were used for the functional status. Knee instability was assessed objectively by KT-1000 arthrometer. There was no statistically significant difference in baseline demographic characteristics between mTT and AMP groups. At the end of 2 years, no statistically significant difference was noted in the anterior drawer and Lachman's test. Though not significant, IKDC scores and Lysholm's scores showed a better outcome in the AMP group when compared to the mTT group. AMP group showed significantly better outcome with KT-1000 arthrometer. Based on the results obtained, we presume that overall both mTT and AMP have similar functional outcome. However, as AMP technique offers significantly improved subjective rotational stability on pivot shift test, better hop limb symmetry index and KT 1000 readings compared to mTT, we suggest AMP over mTT.
\end{abstract}

Keywords Transtibial technique $\cdot$ Anteromedial portal $\cdot$ Transportal technique $\cdot$ ACL reconstruction $\cdot$ Femoral tunnel . Transfixation

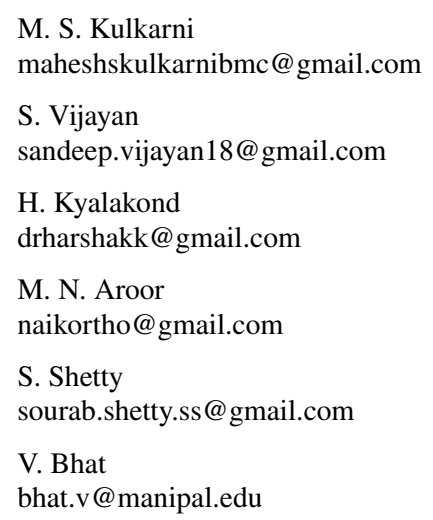

\section{S. K. Rao}

skraok@yahoo.com

1 Department of Orthopedics, Kasturba Medical College, Manipal, Manipal Academy of Higher Education, Manipal, Udupi, Karnataka 576104, India

2 Department of Orthopedics, BVVS S Nijalingappa Medical College and HSK Hospital and Research Centre, Navanagar, Bagalkot, Karnataka 587103, India

3 Department of Physiotherapy, Manipal College of Health Professions, Manipal Academy of Higher Education, Manipal, Karnataka 576104, India 


\section{Introduction}

Anterior cruciate ligament (ACL) injuries are one of the most common ligament injuries occurring in young and active individuals and lead to substantial economic burden $[1,2]$. ACL being an intra-articular and extra-synovial structure mainly offers anteroposterior stability apart from rotational and coronal plane stability. Untreated complete ACL tear alters the tibiofemoral kinematics and leads to functional impairment, secondary meniscal injury, chondral damage and development of early arthritis [3-6]. The peculiar anatomy of ACL, extra-synovial location, lower vascularity, lack of clot formation, retraction of torn ends by synovial myofibroblasts, poor cellular response of ligament fibroblasts in the form of lower proliferation, migration and responsiveness to growth factors and pull of quadriceps muscle impede spontaneous healing of a completely torn ACL [7]. Hence, arthroscopic ACL reconstruction, which is considered as the current standard care of treatment, becomes the viable option to restore the functional status and prevent secondary injuries of the knee [8]. The surgical outcome depends on the graft selection, thickness and length of the graft, tunnel positions in the tibia and femur, graft fixation methods in the tunnel and rehabilitation [9-11].

Anatomical positioning of the graft at the tibial and femoral footprint has been shown to have better kinematics [12]. For the creation of the femoral tunnel, five methods have been described, namely transtibial (TT), modified transtibial (mTT), anteromedial or transportal technique (AMP), outside-in (OI) technique and outside-in retrograde drilling (RD) technique [13, 14]. Since 1980, the transtibial technique was the widely used technique world over [15]. One of the problems noted with TT technique was the position of the femoral tunnel, which places the graft high in the intercondylar notch in a non-anatomical position rather than at the native ACL footprint [16]. Many authors have suggested various modifications in TT technique in an attempt to create a more anatomical femoral tunnel position termed as modified TT (mTT) technique [17-19]. Compared to TT, mTT and AMP techniques lead to more anatomical placement of the ACL graft. Various cadaveric, kinematic, biomechanical and radiological studies have assessed the difference between TT and more anatomical mTT and AMP techniques with regard to the graft placement $[12,14,20,21]$. Many studies have given conflicting verdict about the clinical and functional outcome of both these techniques [11, 22-27]. As mTT and AMP technique aims at anatomical placement of the femoral tunnel albeit with different methods, we designed a retrospective comparative study to analyse the clinical and functional outcomes of ACL reconstruction using mTT and AMP techniques. We hypothesized that there would be no difference between the clinical and functional outcomes in mTT and AMP techniques of ACL reconstruction.

\section{Materials and methods}

This retrospective observational study was conducted in the year 2017 using the data of patients who were operated in 2014 and 2015. Consecutive patients who underwent arthroscopic ACL reconstruction using semitendinosus-gracilis (STG) quadrupled graft in our tertiary care centre with a minimum follow-up of two years were included. Skeletally immature patients, revision ACL surgery, associated tibial plateau/femoral condyle fracture, associated intra-articular avulsion fractures of the tibial spine, posterior cruciate ligament (PCL) injuries, collateral ligament injuries, prior collateral ligament surgeries and bilateral ACL deficiencies were excluded. Data regarding ACL deficiency, which was evaluated by clinical tests and confirmed by MRI, were retrieved from the hospital medical records and PACS (picture archiving and communication system). Their surgical details were collected from the operation notes. Written informed consent was obtained from the patients. Institutional ethics committee (IEC) approval was obtained for the study. They were categorized into two groups based on the femoral tunnel drilling method, as modified transtibial (mTT) or anteromedial portal (AMP) technique, which was decided at the discretion of the operating surgeon.

\section{Surgical technique}

All the patients were examined under anaesthesia. Objective testing was done using KT-1000, and the results were noted down. Diagnostic arthroscopy followed by meniscal balancing was done in the cases deemed necessary. All the cases were operated by a single senior surgeon. STG graft from the ipsilateral side was harvested, prepared, quadrupled and sized.

ACL remnant was debrided retaining the tibial stump. As described by Morgan et al., the tibial tunnel was drilled centring over tibial footprint using the tibial zig placed at an angle of $50^{\circ}$ in the sagittal plane and $20^{\circ}$ in the coronal plane with the knee flexed at $90^{\circ}$ [28].

The femoral tunnel preparation in the mTT group was made as described by Lee et al. [29]. With the knee in $90^{\circ}$ flexion, more anatomical femoral tunnel was created by applying anterior drawer force, varus stress, external rotation of the tibia and external rotation of the femoral offset guide and directing the jig towards the anatomic centre of the ACL footprint. A guidewire was passed through the jig, and inner-to-outer cortical drilling was done with a 4-mm drill bit (Fig. 1a, b). The entire length of the femoral tunnel was 


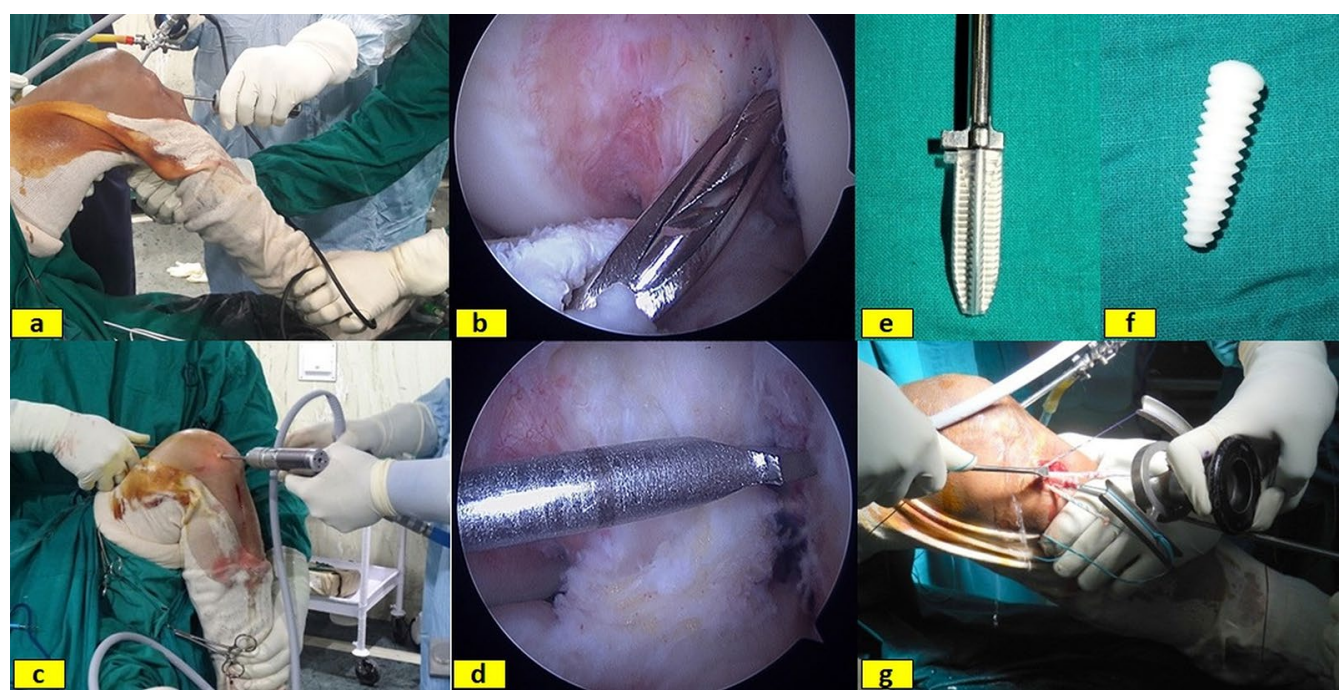

Fig. 1 Photograph depicting external (a) and internal (b) images of femoral tunnel creation using modified transtibial (mTT) technique. External (c) and internal (d) images of femoral tunnel creation by

measured, and femoral tunnel drilled to a depth of $35 \mathrm{~mm}$ corresponding to the diameter of the graft.

In the AMP group, the midpoint of the femoral footprint was identified and the calibrated guidewire was passed from that point with the knee in maximum flexion (Fig. 1c, d). The tunnel was drilled to a depth of $35 \mathrm{~mm}$ using the drill bit corresponding to the diameter of the graft. The length of the tunnel was marked on the graft to confirm correct insertion length. The STG graft was transfixed in the femoral tunnel using two Depuy Mitek rigidfix ${ }^{\circledR}$ femoral ST cross pins in both techniques. With the knee at $30^{\circ}$ of flexion and a posterior drawer force applied to the proximal tibia, the graft was anchored in the tibial tunnel using Depuy bioabsorbable interference screw with sheath maintaining a tension of $15 \mathrm{lbs}$ with the help of a tensioner (Fig. 1e-g). Post-operatively compression dressing and knee immobilizer were applied. The post-operative protocol was same for both the techniques (Table 1). anteromedial portal (AMP) technique. Tibial sheath (e), interference screw (f) and graft fixation in the tibial tunnel with the help of the graft tensioner (g)

At the final follow-up, two years after the index procedure, all patients were assessed clinically by a trained orthopaedic resident who was not involved in the initial surgical management of these patients. Anterior drawer, Lachman's, pivot shift and single-legged hop symmetry index were tested to assess the stability of the operated knee. Lysholm Knee Scoring Scale and International Knee Documentation Committee (IKDC) subjective knee evaluation score were used to document the functional status [1]. Knee instability was assessed objectively by KT-1000 arthrometer. KT-1000 arthrometer values at $20 \mathrm{lbs}(89 \mathrm{~N})$ were recorded, and side-to-side difference was calculated. (Values were expressed as the difference between the operated and healthy knees). Hop limb symmetry index (LSI) as described by Noyes et al. [30] was expressed as the percentage of the longest 'involved limb' hop distance divided by the longest 'uninvolved limb' hop distance.

Table 1 Post-operative rehabilitation protocol for both the groups

1st week: Isometric and short arc quadriceps (300 short of full extension), auto-assisted knee flexion

2nd week and 3rd week: Resisted quadriceps exercises, sitting knee flexion, static quadriceps at $80^{\circ}$ of flexion, prone knee bends, single-leg bridges

4th week: Full weight-bearing walking, stationary cycling with both legs $30^{\circ}$ short of full extension, backward walking, wall sits $0-45^{\circ}$

8th week: single $2 / 3$ knee bends, 6-inch step-ups, resisted quadriceps full ROM, stationary cycling with resistance

12th week: Wobble board, mini trampoline, jogging if quadriceps is at least $65 \%$ normal

16th week: Cariocas, jumping rope, resisted quadriceps throughout $\mathrm{ROM}^{\mathrm{a}}$

6 months: Sports-specific activities if the knee is stable

8 months: Pivoting sports

9 months: Unrestricted sports

${ }^{a} R O M$ range of movement 


\section{Statistical analysis}

Descriptive statistics were used to summarize the characteristics of both groups. Categorical variables of the clinical tests (anterior drawer, Lachman and pivot shift tests), Lysholm knee score and KT-1000 arthrometer measurements were compared using Fisher's exact test. Independent-samples test was employed to compare both groups for single-legged hop test, IKDC scores and KT-1000 readings. SPSS Statistics, IBM Corp®. version 20.0 was used to analyse the data. In all analyses, the $p$ value of $<0.05$ indicated a statistically significant difference. Post hoc power analysis was done using OpenEpi version 3.

\section{Results}

Of the 81 consecutive patients, only 76 fulfilled the inclusion criteria. (One case each of revision ACL reconstruction, tibial plateau fracture, contralateral ACL reconstruction and two cases of MCL repair were excluded.) Seven cases were not having follow-up of 2 years, and only the remaining 69 cases were considered for the study.

The majority were males (62/69), having the involvement of the right knee (41/69). Mean age of the patients was $30.22( \pm 9.34)$ yrs. Road traffic accident (RTA) was the most common mode of injury (32/69) followed by sports injuries and fall. Out of 69 patients, 42 had associated meniscal involvement. Out of 42 cases, 13 had involvement of both the menisci. Out of 69 patients, 37 had undergone ACL reconstruction by mTT technique and remaining by AMP technique (Table 2).

There was no statistically significant difference between mTT and AMP groups with respect to the age, gender, duration since the injury, affected side, involvement of the meniscus, Lachman test, anterior drawers test and KT 1000 values (Table 3). At the end of 2 years, no statistically significant difference was noted in the anterior drawer and Lachman's test among the two groups. IKDC scores were better in the AMP group, but the difference was not statistically significant. It was also observed that the average IKDC score in patients with isolated ACL injury (88.57) was better than in those associated with meniscal injuries (86.28). Lysholm's scores showed a better outcome in the AMP group with $75.4 \%$ patients having excellent scores compared to mTT group in which only $62.2 \%$ of patients had excellent scores. However, this was not statistically significant. In our series, we had no grade 2 or 3 pivot shift positive cases. Grade 1 positive pivot shift was observed in 11 patients in the mTT group and 3 patients in the AMP group, and this difference was noted to be statistically significant. Average hop limb symmetry index (LSI) was 87.26 for the mTT group and 90.13 for the AMP group, and the difference was statistically
Table 2 Demographic distribution of patients

\begin{tabular}{ll}
\hline Variables & All patients $( \pm$ SD) \\
\hline No. of patients & 69 \\
Male/female & $62 / 7$ \\
Age in years & $30.22( \pm 9.34)$ \\
Affected side & \\
Right/left & $41 / 28$ \\
Mode of injury & \\
RTA $^{\text {a }}$ & $32(46.4 \%)$ \\
Fall & $17(24.6 \%)$ \\
Sports injury & $20(29 \%)$ \\
Meniscus injury & $42 / 69$ \\
Medial meniscus & 20 \\
Lateral meniscus & 09 \\
Both Menisci & 13 \\
Duration in months & $12.77( \pm 15.88)$ \\
Surgical technique & \\
Modified transtibial & 37 \\
Anteromedial portal & 32 \\
\hline
\end{tabular}

${ }^{\mathrm{a}} R T A$ road traffic accident

significant, thereby inferring that AMP technique offers better dynamic knee stability as compared to mTT technique. Also, KT-1000 arthrometer values in the AMP group showed significantly better results compared to mTT group, thereby suggesting that AMP technique offers better anteroposterior and rotational stability in comparison with the mTT technique (Table 4). We also evaluated the correlation among the measuring tools. Single-hop limb symmetry index, IKDC score and KT-1000 measurements all were correlating significantly and in agreement with each other (Fig. 2) and (Table 5).

Our retrospective study had 37 patients in mTT and 32 patients in the AMP group. Post hoc power analysis showed that our study was adequately powered for hop limb symmetry index (87.82\%) and KT 1000 arthrometer readings (96.56\%) with an alpha error of $5 \%$ by the normal approximation method.

\section{Discussion}

Many cadaveric, biomechanical, kinematic and radiological studies have revealed the advantages of anatomical positioning of the ACL graft [12, 31, 32]. It has been observed that the TT technique places the graft in a non-anatomical position in the intercondylar region $[10,16,23,31]$. Due to the tibial tunnel constraints, femoral tunnel will be placed more superior and anterior in the femoral condyle by TT technique $[33,34]$. AMP technique facilitates femoral tunnel drilling in the centre of the footprint and hence anatomical positioning 
Table 3 Comparison of demographic and preoperative evaluation findings between the two groups

\begin{tabular}{|c|c|c|c|c|}
\hline & Total & $\mathrm{mTT}^{\mathrm{a}}$ & $\mathrm{AMP}^{\mathrm{b}}$ & $p$ value \\
\hline Gender & & & & 0.696 \\
\hline Male & 62 & $34(91.9 \%)$ & $28(87.5 \%)$ & \\
\hline Female & 7 & $3(8.1 \%)$ & $4(12.5 \%)$ & \\
\hline Side affected & & & & 1.000 \\
\hline Right & 41 & $22(59.5 \%)$ & $19(59.4 \%)$ & \\
\hline Left & 28 & $15(40.5 \%)$ & $13(40.6 \%)$ & \\
\hline Age in years & $30.22( \pm 9.34)$ & $29.03( \pm 9.18)$ & $31.59( \pm 9.46)$ & 0.258 \\
\hline Duration in months & $12.77( \pm 15.88)$ & $13.02( \pm 14.51)$ & $12.49( \pm 17.56)$ & 0.892 \\
\hline \multicolumn{5}{|l|}{ Meniscus status } \\
\hline Medial meniscus & & & & 0.148 \\
\hline Healthy & 36 & $16(43.4 \%)$ & $20(62.5 \%)$ & \\
\hline Torn & 33 & $21(56.8 \%)$ & $12(37.5 \%)$ & \\
\hline Lat Meniscus & & & & 1.000 \\
\hline Healthy & 47 & $25(67.6 \%)$ & $22(68.8 \%)$ & \\
\hline Torn & 22 & $12(32.4 \%)$ & $10(31.2 \%)$ & \\
\hline Preoperative anterior drawers test & 56 & 30 & 26 & 0.531 \\
\hline Grade 0 & 0 & 0 & 0 & \\
\hline Grade 1 & 1 & 0 & $1(3.8 \%)$ & \\
\hline Grade 2 & 32 & $18(60 \%)$ & $14(53.8 \%)$ & \\
\hline Grade 3 & 23 & $12(40 \%)$ & $11(42.3 \%)$ & \\
\hline Preoperative Lachman test & 56 & 30 & 26 & 0.601 \\
\hline Grade 0 & 0 & 0 & 0 & \\
\hline Grade 1 & 0 & 0 & 0 & \\
\hline Grade 2 & 26 & $15(50 \%)$ & $11(42.3 \%)$ & \\
\hline Grade 3 & 30 & $15(50 \%)$ & $15(57.7 \%)$ & \\
\hline KT-1000 (Preoperative) (mm) & $7.39( \pm 1.82)$ & $7.54( \pm 1.86)$ & $7.22( \pm 1.79)$ & 0.46 \\
\hline
\end{tabular}

$* p<0.05$ is considered as statistically significant

${ }^{\mathrm{a}} m T T$ modified transtibial technique

${ }^{\mathrm{b}} A M P$ anteromedial portal technique of the graft $[12,16,23,31,35]$. Vertical placement of the graft in TT technique gives adequate anteroposterior stability for the knee, but limited rotational stability [11, 18, 24]. However, improved anteroposterior, as well as rotational stability, can be achieved by slight horizontal placement of the graft as in the AMP technique [32,36-38]. This finding is corroborated by Schairer et al. [21] in their in vivo study of reconstructed ACL by AMP and TT technique using MRI. Shorter femoral tunnel, higher risk of posterior wall blow out, the requirement of high flexion of the knee and scuffing of the medial femoral condyle by the drill are few of the criticism against the AMP technique [22, 34].

The posterolateral bundle of ACL along with anterolateral ligament complex (iliotibial band with its deep and capsulo-osseous layer, Kaplan fibres, lateral capsule, and mid-third capsular ligament), posterior horn of lateral and medial meniscus and bony morphology of distal femur provide rotatory stability to the knee joint in extension [39-41]. The anatomic double-bundle ACL reconstruction technique by virtue of recreating posterolateral bundle shows better rotational stability than single-bundle technique [39-42]. However, evidence for clinical and biomechanical benefits of double-bundle ACL reconstruction is still debated to date [41]. Sonnery-Cottet et al. [42] described that performing an additional extra-articular lateral reconstruction procedure along with standard single-bundle ACL reconstruction is more effective than isolated single- or anatomic doublebundle reconstruction and prevented the displacement of the lateral tibial compartment. But, some studies have failed to demonstrate outcomes in favour of the lateral tenodesis too [41, 42].

Many authors have described various modifications in TT technique to achieve more anatomical position of the femoral tunnel. Medializing and taking more proximal entry point for the tibial tunnel is one such technique. Injury to the MCL, widened tibial aperture and shorter tibial tunnel are the risks involved in this method [43]. Another described method is to use a smaller femoral drill and do incremental drilling by readjusting the guidewire so that it has some play in the larger tibial tunnel and thereby try to achieve better 
Table 4 Comparison of postoperative clinical evaluation and functional outcome among the two groups

\begin{tabular}{|c|c|c|c|c|}
\hline & All the patients & $\mathrm{mTT}^{\mathrm{a}}$ & $\mathrm{AMP}^{\mathrm{b}}$ & $p$ value \\
\hline Post-operative anterior drawers test & & & & 0.77 \\
\hline Grade 0 & 42 & $21(56.8 \%)$ & $21(65.6 \%)$ & \\
\hline Grade 1 & 24 & $14(37.8 \%)$ & $10(31.3 \%)$ & \\
\hline Grade 2 & 3 & $2(5.4 \%)$ & $1(3.1 \%)$ & \\
\hline Grade 3 & 0 & 0 & 0 & \\
\hline Post-operative Lachman test & & & & 0.59 \\
\hline Grade 0 & 34 & $16(43.2 \%)$ & $18(56.3 \%)$ & \\
\hline Grade 1 & 29 & $17(45.9 \%)$ & $12(37.5 \%)$ & \\
\hline Grade 2 & 6 & $4(10.8 \%)$ & $2(6.3 \%)$ & \\
\hline Grade 3 & 0 & 0 & 0 & \\
\hline Post-operative pivot shift test & & & & $0.04 *$ \\
\hline Grade 0 & 55 & $26(70.3 \%)$ & $29(90.6 \%)$ & \\
\hline Grade 1 & 14 & $11(29.7 \%)$ & $3(9.4 \%)$ & \\
\hline Grade 2 & 0 & 0 & 0 & \\
\hline Grade 3 & 0 & 0 & 0 & \\
\hline KT-1000 (2-year follow-up) (mm) & $1.78( \pm 0.92)$ & $2.14( \pm 0.88)$ & $1.38( \pm 0.79)$ & $0.000^{*}$ \\
\hline Post-operative KT-1000 values at $20 \mathrm{lbs}(89 \mathrm{~N})$ & & & & $0.007 *$ \\
\hline$<3$-mm side-to-side difference & 54 & $24(64.9 \%)$ & $30(93.8 \%)$ & \\
\hline 3-5-mm side-to-side difference & 15 & $13(35.1 \%)$ & $02(6.3 \%)$ & \\
\hline Hop limb symmetry index & $88.59( \pm 4.06)$ & $87.26( \pm 4.04)$ & $90.12( \pm 3.56)$ & $0.003^{*}$ \\
\hline IKDC score & $87.17( \pm 4.41)$ & $86.34( \pm 3.97)$ & $88.13( \pm 4.74)$ & 0.092 \\
\hline Post-operative Lysholm's score & & & & 0.56 \\
\hline Excellent & 47 & $23(62.2 \%)$ & $2475.0 \%)$ & \\
\hline Good & 19 & $12(32.4 \%)$ & $07(21.9 \%)$ & \\
\hline Fair & 3 & $2(5.4 \%)$ & $1(3.1 \%)$ & \\
\hline Poor & 0 & 0 & 0 & \\
\hline
\end{tabular}

*p $p<0.05$ Student's $t$ test

${ }^{\mathrm{a}} m T T$ modified transtibial technique

${ }^{\mathrm{b}} A M P$ anteromedial portal technique

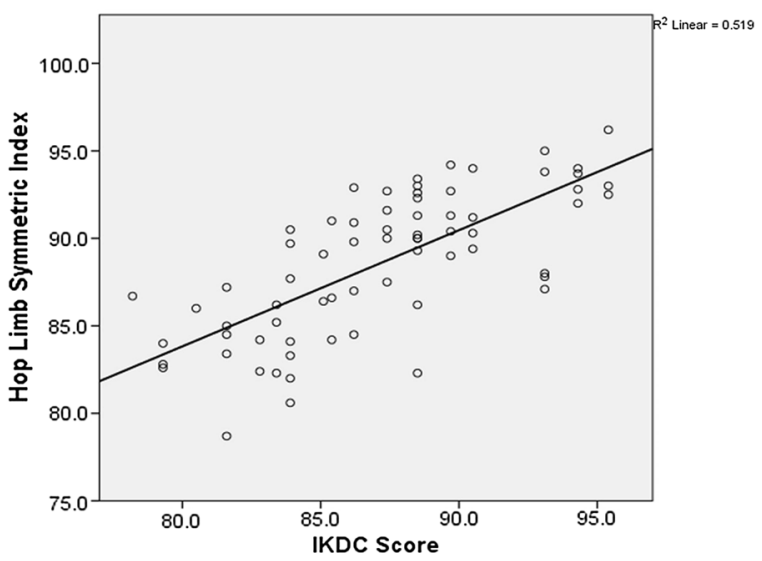

Fig. 2 Scatter plot showing the correlation between hop limb symmetry index and IKDC score

anatomical position [17, 44]. Chung et al. [45] suggested a larger femoral offset guide to achieve anatomical femoral tunnel positioning. Lee et al. [29] described manoeuvre, which can be used to achieve more anatomical positioning of the femoral tunnel. They suggested applying anterior drawer and varus force along with an external rotation of the tibia and external rotation of the femoral offset guide to position the femoral tunnel more posteriorly and horizontally than regular TT technique.

In our study, we found no statistical difference in IKDC score, Lysholm's score and anterior drawers test results between mTT and AMP groups. Our results are similar to the conclusion drawn by Youm et al. and Han et al. [46, 47]. Though in the AMP group the scores were better, it was not statistically significant. Closer scrutinization of the results reveals that the AMP group showed significantly better pivot shift, single-hop limb index scores and KT-1000 results. This is in contrast to the finding of Lee et al. [19] who found no difference between the two groups. We had no cases having KT-1000 laxity $>5 \mathrm{~mm}$, which is similar to the observation made by Youm et al. [46]. But we noted that mTT had significantly more cases which had 3- to 5-mm side-to-side laxity (mTT 13/37 vs AMP 2/32; $p<0.005$ ). 
Table 5 Correlation among the functional assessment tools

\begin{tabular}{lccc}
\hline Correlation & Pearson correlation & $p$-value & $R^{2 \mathrm{a}}$ \\
\hline Hop limb symmetry index Vs IKDC score & 0.721 & $0.000^{*}$ & 0.519 \\
Hop limb symmetry index Vs KT-1000 & -0.686 & $0.000^{*}$ & 0.470 \\
KT-1000 Vs IKDC score & -0.668 & $0.000^{*}$ & 0.447 \\
\hline${ }^{*} p<0.05$ & & & \\
${ }^{\mathrm{a}} R^{2}:$ correlation coefficient & & &
\end{tabular}

Though mTT aimed at producing anatomical femoral tunnel comparable to AMP technique, the femoral tunnels that are produced by mTT are less oblique compared to AMP technique [43]. Increased obliquity of the graft placement by AMP technique improves the rotational stability, which has been proved by biomechanical studies as well [37]. This improved rotational stability due to increased obliquity of the graft placement in AMP technique can explain the difference seen in our results.

We used the ST cross pins for transfixing the graft in the femoral tunnel, which allows for maximum contact between the graft and the host bone avoiding any dead space in the tunnel. And it also addresses issues with posterior wall blow out seen mostly with AMP technique. Hyper flexing the knee to $110^{\circ}$ while drilling the femoral tunnel will result in creation of a tunnel of sufficient length by AMP technique [48]. Other criticism on AMP is about damaging the medial femoral condyle cartilage while drilling the femoral tunnel. This can be avoided by careful technique and making low AM portal or 2 AM portals and start drilling only once the drill bit contacts the femoral footprint [26].

In our study, we did not have any major complications. Postoperatively, none of our patients had grade 3 instability to suggest a re-rupture of the graft. In two patients, we had to remove the tibial interference screw due to its prominence. But since the patients became symptomatic only after more than 2 years, it did not change the outcome.

Strengths of this study are that it is a single-centre study, all cases operated by an experienced single surgeon and all patients were managed by a standard protocol. There was no significant demographic difference among the group with the acceptable number of loss of follow-up of the cases (90.8\% completed the follow-up at 2 yrs). Both the groups were identical and comparable except for the technique for the femoral tunnel drilling. Post hoc power analysis revealed that our study was adequately powered. Our study has few limitations. Ours is a retrospective observational study. We did not evaluate for the position of the graft and tunnels radiologically in the post-op period, which would have confirmed the difference in the graft positioning among these two techniques. We found it an unnecessary exercise as there are many studies in the literature, which already have proven the point [47]. Ours is a short-term study, which is not expected to reveal the prevention of further injuries to the meniscus and development of osteoarthritis changes. A well-constructed double-blinded randomized controlled trial with an adequate number of participants comparing mTT and AMP techniques with sufficient long-term follow-up can address these issues.

Based on the results obtained, we believe that overall both MTT and AMP have similar functional outcome. We do acknowledge that our study has its own inherent limitations due to the retrospective non-randomized design and shortterm follow-up. But, as AMP technique offers improved subjective rotational stability on pivot shift test, better hop limb symmetry index and KT 1000 readings at 2 years, we suggest AMP over mTT.

Funding Open access funding provided by Manipal Academy of Higher Education, Manipal.

\section{Declarations}

Conflict of interest The authors declare that they have no conflict of interest.

Open Access This article is licensed under a Creative Commons Attribution 4.0 International License, which permits use, sharing, adaptation, distribution and reproduction in any medium or format, as long as you give appropriate credit to the original author(s) and the source, provide a link to the Creative Commons licence, and indicate if changes were made. The images or other third party material in this article are included in the article's Creative Commons licence, unless indicated otherwise in a credit line to the material. If material is not included in the article's Creative Commons licence and your intended use is not permitted by statutory regulation or exceeds the permitted use, you will need to obtain permission directly from the copyright holder. To view a copy of this licence, visit http://creativecommons.org/licenses/by/4.0/.

\section{References}

1. Tegner Y, Lysholm J (1985) Rating systems in the evaluation of knee ligament injuries. Clin Orthop Relat Res 43-49

2. Gottlob CA, Baker CL, Pellissier JM, Colvin L (1999) Cost effectiveness of anterior cruciate ligament reconstruction in young adults. Clin Orthop Relat Res 272-282

3. Finsterbush A, Frankl U, Matan Y, Mann G (1990) Secondary damage to the knee after isolated injury of the anterior cruciate ligament. Am J Sports Med 18:475-479. https://doi.org/10.1177/ 036354659001800505 
4. Irvine GB, Glasgow MM (1992) The natural history of the meniscus in anterior cruciate insufficiency. Arthroscopic analysis. J Bone Joint Surg Br 74:403-405

5. Adamczyk G (2002) ACL—deficient knee Kolano bez wiæzadÆa $\mathrm{krzy}^{\mathrm{O}}$ owego przedniego. Acta Clinica 2:11-16

6. Georgoulis AD, Papadonikolakis A, Papageorgiou CD et al (2003) Three-dimensional tibiofemoral kinematics of the anterior cruciate ligament-deficient and reconstructed knee during walking. Am J Sports Med 31:75-79. https://doi.org/10.1177/0363546503 0310012401

7. Murray MM, Spindler KP (2005) Anterior cruciate ligament healing and repair. Sports Med Arthrosc Rev 13:151-155. https://doi. org/10.1097/01.jsa.0000173243.92319.da

8. Duquin T, Wind W, Fineberg M et al (2009) Current trends in anterior cruciate ligament reconstruction. J Knee Surg 22:7-12. https://doi.org/10.1055/s-0030-1247719

9. Adams D, Logerstedt D, Hunter-Giordano A et al (2012) Current concepts for anterior cruciate ligament reconstruction: a criterion-based rehabilitation progression. J Orthop Sports Phys Ther 42:601-614. https://doi.org/10.2519/jospt.2012.3871

10. Howell SM, Gittins ME, Gottlieb JE et al (2001) The relationship between the angle of the tibial tunnel in the coronal plane and loss of flexion and anterior laxity after anterior cruciate ligament reconstruction. Am J Sports Med 29:567-574. https://doi.org/10. 1177/03635465010290050801

11. Ro K-H, Kim H-J, Lee D-H (2018) The transportal technique shows better clinical results than the transtibial techniques for single-bundle anterior cruciate ligament reconstruction. Knee Surg Sports Traumatol Arthrosc 26:2371-2380. https://doi.org/ 10.1007/s00167-017-4786-1

12. Steiner ME, Battaglia TC, Heming JF et al (2009) Independent drilling outperforms conventional transtibial drilling in anterior cruciate ligament reconstruction. Am J Sports Med 37:19121919. https://doi.org/10.1177/0363546509340407

13. Ponzo A, Monaco E, Basiglini L et al (2018) Long-term results of anterior cruciate ligament reconstruction using hamstring grafts and the outside-in technique: a comparison between 5- and 15-year follow-up. Orthop J Sports Med 6:1-8. https://doi.org/10. $1177 / 2325967118792263$

14. Abebe ES, Moorman CT, Dziedzic TS et al (2009) Femoral tunnel placement during anterior cruciate ligament reconstruction: an in vivo imaging analysis comparing transtibial and 2-incision tibial tunnel-independent techniques. Am J Sports Med 37:19041911. https://doi.org/10.1177/0363546509340768

15. Chhabra A, Diduch DR, Blessey PB, Miller MD (2004) Recreating an acceptable angle of the tibial tunnel in the coronal plane in anterior cruciate ligament reconstruction using external landmarks. Arthroscopy 20:328-330. https://doi.org/10.1016/j.arthro. 2003.11.034

16. Kopf S, Forsythe B, Wong AK et al (2012) Transtibial ACL reconstruction technique fails to position drill tunnels anatomically in vivo 3D CT study. Knee Surg Sports Traumatol Arthrosc 20:2200-2207. https://doi.org/10.1007/s00167-011-1851-z

17. Lee DW, Kim JG (2017) Anatomic single-bundle anterior cruciate ligament reconstruction using the modified transtibial technique. Arthrosc Tech 6:e227-e232. https://doi.org/10.1016/j.eats.2016. 09.028

18. Wallace M, Bedi A, Lesniak BP et al (2011) What effect does anterior cruciate ligament tibial guide orientation have on tibial tunnel length? Arthroscopy 27:803-808. https://doi.org/10.1016/j. arthro.2011.01.009

19. Lee JK, Lee S, Seong SC, Lee MC (2014) Anatomic single-bundle ACL reconstruction is possible with use of the modified transtibial technique: a comparison with the anteromedial transportal technique. J Bone Joint Surg Am 96:664-672. https://doi.org/10. 2106/JBJS.M.00088
20. Kopf S, Martin DE, Tashman S, Fu FH (2010) Effect of tibial drill angles on bone tunnel aperture during anterior cruciate ligament reconstruction. J Bone Joint Surg Am 92:871-881. https://doi.org/ 10.2106/JBJS.H.01680

21. Schairer WW, Haughom BD, Morse LJ et al (2011) Magnetic resonance imaging evaluation of knee kinematics after anterior cruciate ligament reconstruction with anteromedial and transtibial femoral tunnel drilling techniques. Arthrosc J Arthrosc Rela Surg 27:1663-1670. https://doi.org/10.1016/j.arthro.2011.06.032

22. Chen H, Tie K, Qi Y et al (2017) Anteromedial versus transtibial technique in single-bundle autologous hamstring ACL reconstruction: a meta-analysis of prospective randomized controlled trials. J Orthop Surg Res 12:1-10. https://doi.org/10.1186/ s13018-017-0671-3

23. Arno S, Bell CP, Alaia MJ et al (2016) Does anteromedial portal drilling improve footprint placement in anterior cruciate ligament reconstruction? Clin Orthop Rela Res® 474:1679-1689. https:// doi.org/10.1007/s11999-016-4847-7

24. Azboy İ, Demirtaş A, Gem M et al (2014) A comparison of the anteromedial and transtibial drilling technique in ACL reconstruction after a short-term follow-up. Arch Orthop Trauma Surg 134:963-969. https://doi.org/10.1007/s00402-014-1996-6

25. Franceschi F, Papalia R, Rizzello G et al (2013) Anteromedial portal versus transtibial drilling techniques in anterior cruciate ligament reconstruction: any clinical relevance? A retrospective comparative study. Arthroscopy 29:1330-1337. https://doi.org/ 10.1016/j.arthro.2013.05.020

26. Kim M-K, Lee B-C, Park J-H (2011) Anatomic single bundle anterior cruciate ligament reconstruction by the two anteromedial portal method: the comparison of transportal and transtibial techniques. Knee Surg Relat Res 23:213-219. https://doi.org/10. 5792/ksrr.2011.23.4.213

27. Koutras G, Papadopoulos P, Terzidis IP et al (2013) Short-term functional and clinical outcomes after ACL reconstruction with hamstrings autograft: transtibial versus anteromedial portal technique. Knee Surg Sports Traumatol Arthrosc 21:1904-1909. https://doi.org/10.1007/s00167-012-2323-9

28. Morgan CD, Kalman VR, Grawl DM (1995) Definitive landmarks for reproducible tibial tunnel placement in anterior cruciate ligament reconstruction. Arthroscopy 11:275-288

29. Lee JK, Lee S, Seong SC, Lee MC (2014) Modified transtibial technique for anterior cruciate ligament reconstruction with quadriceps tendon autograft: JBJS essential surgical. Techniques 4:e15. https://doi.org/10.2106/JBJS.ST.N.00078

30. Noyes FR, Barber SD, Mangine RE (1991) Abnormal lower limb symmetry determined by function hop tests after anterior cruciate ligament rupture. Am J Sports Med 19:513-518. https://doi.org/ $10.1177 / 036354659101900518$

31. Guler O, Mahırogulları M, Mutlu S et al (2016) Graft position in arthroscopic anterior cruciate ligament reconstruction: anteromedial versus transtibial technique. Arch Orthop Trauma Surg 136:1571-1580. https://doi.org/10.1007/s00402-016-2532-7

32. Kazemi SM, Abbasian MR, Esmailijah AA et al (2017) Comparison of clinical outcomes between different femoral tunnel positions after anterior cruciate ligament reconstruction surgery. Arch Bone Jt Surg 5:419-425

33. Lee D-H, Kim H-J, Ahn H-S, Bin S-I (2016) Comparison of femur tunnel aperture location in patients undergoing transtibial and anatomical single-bundle anterior cruciate ligament reconstruction. Knee Surg Sports Traumatol Arthrosc 24:3713-3721. https://doi. org/10.1007/s00167-015-3657-x

34. Robin BN, Jani SS, Marvil SC et al (2015) Advantages and disadvantages of transtibial, anteromedial portal, and outside-in femoral tunnel drilling in single-bundle anterior cruciate ligament reconstruction: a systematic review. Arthrosc J Arthrosc Relat Surg 31:1412-1417. https://doi.org/10.1016/j.arthro.2015.01.018 
35. Osti M, Krawinkel A, Ostermann M et al (2015) Femoral and tibial graft tunnel parameters after transtibial, anteromedial portal, and outside-in single-bundle anterior cruciate ligament reconstruction. Am J Sports Med 43:2250-2258. https://doi.org/ $10.1177 / 0363546515590221$

36. Harner CD, Honkamp NJ, Ranawat AS (2008) Anteromedial portal technique for creating the anterior cruciate ligament femoral tunnel. Arthroscopy 24:113-115

37. Loh JC, Fukuda Y, Tsuda E et al (2003) Knee stability and graft function following anterior cruciate ligament reconstruction: comparison between 11 o'clock and 10 o'clock femoral tunnel placement. 2002 Richard O'Connor Award paper. Arthroscopy 19:297-304. https://doi.org/10.1053/jars.2003.50084

38. Rayan F, Nanjayan SK, Quah C et al (2015) Review of evolution of tunnel position in anterior cruciate ligament reconstruction. World J Orthop 6:252-262. https://doi.org/10.5312/wjo.v6.i2.252

39. Ferretti A, Monaco E, Vadalà A (2014) Rotatory instability of the knee after ACL tear and reconstruction. J Orthopaed Traumatol 15:75-79. https://doi.org/10.1007/s10195-013-0254-y

40. Colombet P, Jenny JY, Menetrey J et al (2012) Current concept in rotational laxity control and evaluation in ACL reconstruction. Orthop Traumatol Surg Res 98:S201-S210. https://doi.org/10. 1016/j.otsr.2012.10.005

41. Lucidi GA, Hughes JD, Herbst E, et al (2017) Role of the anterolateral complex in rotatory instability of the anterior cruciate ligament deficient knee. Ann Jt 2

42. Sonnery-Cottet B, Thaunat M, Freychet B et al (2015) Outcome of a combined anterior cruciate ligament and anterolateral ligament reconstruction technique with a minimum 2-year follow-up. Am J Sports Med 43:1598-1605. https://doi.org/10.1177/0363546515 571571

43. Chang CB, Choi J-Y, Koh IJ et al (2011) Comparisons of femoral tunnel position and length in anterior cruciate ligament reconstruction: modified transtibial versus anteromedial portal techniques. Arthrosc J Arthrosc Relat Surg 27:1389-1394. https:// doi.org/10.1016/j.arthro.2011.06.013

44. Hussin E, Aldaheri A, Alharbi H, Farouk H (2018) Modified transtibial versus anteromedial portal techniques for anterior cruciate ligament reconstruction, a comparative study. Open Access J Sports Med 9:199-213. https://doi.org/10.2147/OAJSM.S157729

45. Chung JY, Ha C-W, Lee D-H et al (2016) Anatomic placement of the femoral tunnel by a modified transtibial technique using a large-offset femoral tunnel guide: a cadaveric study. Knee 23:659665. https://doi.org/10.1016/j.knee.2015.10.001

46. Youm Y-S, Cho S-D, Lee S-H, Youn C-H (2014) Modified transtibial versus anteromedial portal technique in anatomic singlebundle anterior cruciate ligament reconstruction: comparison of femoral tunnel position and clinical results. Am J Sports Med 42:2941-2947. https://doi.org/10.1177/0363546514551922

47. Han JK, Chun KC, Lee SI et al (2019) Comparison of modified transtibial and anteromedial portal techniques in anatomic singlebundle ACL reconstruction. Orthopedics 42:83-89. https://doi. org/10.3928/01477447-20190211-04

48. Gali JC, de Sousa Oliveira HC, Ciancio BA et al (2012) Femoral tunnel's length changes with knee flexion angle in anatomical anterior cruciate ligament reconstruction. Revista Brasileira de Ortopedia (English Edition) 47:246-250. https://doi.org/10.1016/ S2255-4971(15)30094-X

Publisher's Note Springer Nature remains neutral with regard to jurisdictional claims in published maps and institutional affiliations. 